\title{
Etnozoología andina: Concepciones e interacciones del hombre andino con la fauna altiplánica
}

María Ester Grebe ${ }^{1}$

\section{Introducción}

Intentando descubrir cómo construye el hombre común su mundo de experiencia reflejado en la terminología nativa, y cómo lo ordena, categoriza y clasifica, los antropólogos cognitivos han llegado a la etnociencia (Sturtevant 1968: 475). Esta última se asocia al enfoque émico (Pike 1954), "la visión desde dentro" o "la visión del actor", que conoce, comprende y comunica los fenómenos de su propia realidad tal como él los percibe (Frake 1969a: 29; Pelto 1978: 54-60).

Como parte de la etnociencia, que resume el saber sistematizado del hombre común, la etnozoología ordena y codifica los conocimientos empíricos acumulados por la cultura tradicional acerca del reino animal. Su objetivo es hacer comprensibles las nociones existentes sobre los animales de una fauna específica y sus interrelaciones. Así, la etnozoología conecta ideas y unifica conocimientos, constituyendo un segmento importante de "una primera filosofía de la naturaleza" (Durkheim y Mauss 1963: 8). En estas etnozoologías, se manejan categorías y se clasifica, produciéndose "un sistema de nociones jerarquizadas" (Durkheim y Mauss 1963: 8). El orden jerárquico visible en cada taxonomía etnozoológica no encuentra su modelo en la realidad externa o mundo tangible sino en la representación de éste en la mente de los actores y en las percepciones de éstos vinculadas a su experiencia social y transmisión cultural. Como producto de una lógica concreta, toda etnozoología presenta ordenaciones provisorias. Esta calidad provisoria se debe a que su número de relaciones es limitado por el carácter fragmentario y concreto de la realidad observada y del saber desprendido de ella (Grebe 1975: 27). No obstante, en este tipo de ciencia natural "las relaciones concretas entre el hombre y los seres vivos colorean, a veces, con

1 Departamento de Ciencias Sociológicas y Antropológicas, Facultad de Filosofía, Humanidades y Educación, Universidad de Chile. Av. Larraín 9925, Santiago, CHILE. matices afectivos... el universo entero del conocimiento científico" (Lévi-Strauss 1964: 65).

El hombre andino ha producido una etnozoología que refleja sus propias concepciones del reino animal. Esta etnozoología constituye un intento de ordenar sus experiencias y concepciones acerca del medio ambiente natural y su fauna; y de validar y legitimar una concepción propia de "su" realidad. Esta etnozoología es parte integral del sistema ideacional andino y forma parte de una cosmovisión culturalmente específica. En ella, se articulan las relaciones entre el hombre, la naturaleza y lo sobrenatural; entre idea y conducta; entre la concepción cultural y la praxis social; entre la permanencia de un modelo conceptual y su continuo ajuste a las transformaciones que operan en los medios ecológico y sociocultural. Como parte de esta etnozoología andina, aparecen etnocategorías y etnotaxonomías mediante las cuales se construye un sistema de nociones jerarquizadas provisorias.

Puesto que la etnozoología andina corresponde al ámbito del pastoreo de puna, es necesario situar nuestro tópico en la perspectiva brindada por las investigaciones andinas sobre pastoreo nomádico. Durante los últimos veinte años, las investigaciones antropológicas andinas han producido estudios que abarcan una variada gama de tópicos relativos al pastoreo de puna. Destaca el aporte de Murra (1975), quien reconstruye las pautas culturales de los pastores andinos del Tawantinsuyo ofreciendo un panorama global de sus esquemas de comportamiento sumados a algunas creencias y conocimientos. Sus datos facilitan la comparación entre modelos pastoriles andinos del pasado y presente. Un grupo importante de trabajos recientes se ha centrado en el sistema productivo y adaptativo de los pastores de puna, respondiendo a una tendencia general de los estudios sobre pastores nomádicos de la antropología contemporánea que marcan preferencias por el fenómeno económico (Oberem 1967, 1976; Hartmann 1971; Webster 1971, 1973; Fonseca 1972; Thomas 1972; Alberti y Mayer 1974; Mayer 1974; Concha Contreras 1975; Baker 
y Little 1976; Flores Ochoa 1977a; Orlove 1977; Dyson-Hudson 1980: 54;). Otro grupo de estudios ha explorado el sistema ideacional andino, con especial referencia a creencias, prácticas rituales y simbologías (Casaverde 1970; Núñez del Prado 1970; Garr 1972; Nordyke 1972; Earls 1973; Gow 1974; Sallnow 1974; Aranguren 1975; Gow y Gow 1975; Martínez 1976; Bouysse-Cassagne 1978; Cereceda 1978; Isbell 1978; Grebe 1980, 1981; Van Kessel 1980). La perspectiva del cambio sociocultural en marcha de las comunidades de pastores y agricultores andinos es analizada en amplitud por Matos Mar (1976: 204-212) y Lewellen (1977: 195), quienes coinciden en detectar una transformación profunda de estructuras tradicionales andinas bajo el influjo del contacto cultural creciente con la sociedad urbana moderna del litoral, posibilitado por la migración cíclica o definitiva.

Aun cuando el enfoque cognitivo que rescata visiones de mundo de los aymara del norte de Chile ha sido tratado en amplitud (Grebe 1980: 127-190, 1981), no sucede igual con la etnociencia aymara de esta zona. Algunas excepciones a esta regla son: a) dos trabajos exploratorios de etnobotánica (Aldunate et al. 1981: 183-223; Castro et al. 1982: 133-203); b) cuatro estudios de Flores Ochoa sobre pastoreo de Puna, en los cuales se reconstruye una taxonomía quechua de camélidos andinos. Estos últimos presentan versiones diferentes de la taxonomía que culminan en una monografía (Flores Ochoa 1976: 127-129, 1977b: 141, 1977c: 231, 1978: 1006-1016). Estos cuatro trabajos constituyen el antecedente más inmediato a nuestro tópico, puesto que en Chile no se cuenta aún con investigaciones previas de etnozoología andina.

Los contenidos de la taxonomía de camélidos de Flores Ochoa indican que ésta se desprende de una dicotomía básica: animales domesticados y silvestres. A partir de ella, se evoluciona en un orden de concretización creciente, que toma en cuenta los siguientes criterios: origen del animal, presencia o ausencia de lana y tipo de fibra, sexo y fertilidad, edad y color (Flores Ochoa 1976, 1977b, 1977c, 1978). Este mismo autor ofrece, además, datos importantes acerca de las pautas de comportamiento del pastor andino y sus procesos adaptativos y de cambio cultural (1979).

El presente estudio sintetiza resultados del trabajo de terreno realizado en Isluga durante los años 19771978 y 1982. Su propósito es efectuar un estudio etnozoológico a partir de "la visión desde dentro" del pastor. Se intenta identificar las categorías zoológicas émicas y su ordenación taxonómica; y de relacionar las nociones y concepciones del pastor con su praxis del pastoreo.

\section{Material y método}

El universo de estudio del presente trabajo se centra en la comunidad de Isluga, situada en el sector altiplánico colindante con Bolivia, al interior de Iquique en la I Región de Chile. Dada la vigencia de la organización social tradicional de la comunidad en dos saya o mitades y cuatro ayllu, el trabajo se efectuó en dos estancias representativas de las dos mitades; Enquelga (de araj-saya, la alta montaña) y Pisiga-Choque (de manqha-saya, la planicie inferior).

Para la elaboración inicial de la etnotaxonomía zoológica se contó con la colaboración de nueve hombres adultos (incluyendo a un yatiri: adivino, curandero y oficiante ritual), a quienes los miembros de su estancia atribuyeron mayor experiencia como portadores de conocimientos tradicionales y como partícipes en actividades rituales. Para el estudio de la articulación de esta etnotaxonomía con la praxis pastoril, el trabajo se centró en una muestra de 56 niños-pastores de ambos sexos, entre 6 y 14 años, pertenecientes en mitades iguales a las estancias de Enquelga y Pisiga-Choque. La autora del presente trabajo agradece la colaboración prestada por los directores de las escuelas G 69 de Enquelga, señor Rigoberto Letelier, y G 68 de Pisiga-Choque, señor Héctor Briceño, cuya gentil autorización y ayuda posibilitaron un desarrollo eficiente y satisfactorio de esta investigación, para la cual se contó con la totalidad de los alumnos de $1^{\circ}$ a $4^{\circ}$ básico de ambas escuelas.

Puesto que, tanto hoy día como en el pasado (Murra 1975: 119-120), la rutina diaria del pastoreo se ha asignado principalmente, por delegación de funciones, al niño o niña, estos últimos se definen como los actores o protagonistas principales en el estudio de la red de interacciones y concepciones del pastor aymara de Isluga con la fauna altiplánica. En efecto, como resultado de un proceso de transformaciones socioculturales en marcha que se acentúa durante los últimos cinco años por la apertura del puerto libre de Iquique y el mayor acceso a las áreas urbanas, el hombre aymara jefe de una familia extendida o nuclear ha delegado en forma casi permanente la 
tarea del pasteo o pastoreo de puna a su esposa, quien a su vez, con el fin de disponer del tiempo necesario para la actividad doméstica y del tejido a telar, delega la responsabilidad pastoril en sus hijos e hijas previamente entrenados (Flores Ochoa 1979: 69-70). Debe considerarse que este hecho no constituye novedad y es consecuencia de que, tanto en el pasado como en el presente, el pastoreo era "un menester considerado generalmente de bajo status" (Murra 1975:120).

En consecuencia, una parte importante del presente trabajo se concentró en los niños-pastores, transformándolos en etnógrafos de su propia actividad y percepción de su realidad, con el fin de producir fuentes de información primarias de máxima confiabilidad. Como resultado de este trabajo de terreno, se recolectaron tres especies de documentos personales infantiles:

1. Relatos escritos de las actividades desarrolladas en un día completo de pastoreo.

2. Descripciones de los medios de comunicación que permiten hacer más eficientes las tareas del pastoreo.

3. Dibujos de: a) la fauna andina domesticada, y b) la fauna andina silvestre, en los cuales, a modo de mapa cognitivo, el niño pastor identificó cada uno de los animales conocidos, situándolos en su entorno natural (Figuras 1a, b, c. d).

Como control y ampliación de los contenidos de los antedichos documentos primarios, se utilizó la observación participante de las actividades de pastoreo; y entrevistas semiestructuradas a 24 niños pastores de 8 a 13 años, incluyendo entre éstos a niños de las estancias de las mitades de arriba y abajo.

De lo anteriormente expuesto, se infiere que el marco teórico del presente trabajo responde a una orientación cognitiva. Y que sus métodos y técnicas se encuadran en un diseño exploratorio que adapta recursos de la antropología cognitiva y simbólica. En consecuencia, para los fines específicos de reconstruir la etnotaxonomía zoológica de Isluga, se empleó una adaptación del análisis componencial tomado de estudios antropológicos cognitivos (Wallace 1962; Sturtevant 1968; Conklin 1969; Frake 1969a y b). Se trabajó con los conceptos de dominio (universo de estudio de la clasificación), segregado (categoría émica), conjunto de contraste (dicotomía émica) y paradigma (conjunto de segregados y/o conjuntos de contraste susceptibles de ser divididos de acuerdo a sus significados). Se analizó componencialmente cada paradigma, llegando finalmente a reconstruir una taxonomía que ordena e interrelaciona todo lo anterior. Mediante este tipo de análisis, se intentó identificar los principios que permiten reconstruir su realidad percibida. Pero el problema metodológico fundamental radica en que los actores utilizan lógicas de varias dimensiones proyectadas en sus etnotaxonomías (Lévi-Strauss 1964; Sturtevant 1968). Por esta razón, a menudo es difícil establecer la lógica o los ejes lógicos de la taxonomía total. Si bien es posible analizar componencialmente un paradigma o un conjunto de contraste, es imposible aplicar este tipo de análisis a una taxonomía completa (Sturtevant 1968).

\section{Resultados}

Se resumen, a continuación, los hallazgos principales que derivaron del análisis sistemático de datos de esta investigación.

\section{Etnotaxonomía zoológica (Figura 1).}

\section{a) Dominio}

El ámbito clasificatorio total está formado por la fauna de Isluga, incluyendo todos los animales que el hombre aymara reconoce en su hábitat.

b) Conjunto de contraste principal: Domesticadosilvestre

El dominio se bifurca en una dicotomía émica inicial que constituye una gran matriz clasificatoria: animales domesticados y silvestres. A juzgar por los hallazgos de Flores Ochoa en Paratía, Perú (1976, 1978), esta dicotomía parece ser panandina. Descansa en la dicotomía uywa (animal criado, con dueño) y sallka (animal salvaje, sin dueño), compartida en las lenguas aymara y quechua (Bertonio 1879 [1612] II: 371, 306). El Cuadro 1 establece los criterios de contraste de esta dicotomía, que fueron enunciados con exactitud por tres niños pastores (J. Choque et al. 151282).

Esta dicotomía es producto tanto de la experiencia global y actividades productivas del hombre aymara con la fauna como también de sus creencias acerca del origen de los animales. Se cree que en tiempos remotos el espíritu de la montaña (mallku) era poseedor 


\begin{tabular}{|l|l|}
\hline \multicolumn{1}{|c|}{ Uywa (domesticados) } & \multicolumn{1}{c|}{ Sallka (silvestres) } \\
\hline 1. "Tienen dueño". & 1. "No tienen dueño". \\
\hline 2. "Obedecen". & 2. "No obedecen". \\
\hline 3. "Son mansos". & $\begin{array}{l}\text { 3. "Son peleadores. Pelean } \\
\text { entre ellos y con uywa". }\end{array}$ \\
\hline 4. "Son amigos del hombre". & 4. "Arrancan del hombre". \\
\hline 5. "Se conocen bien". & 5. "No se conocen bien". \\
\hline 6. "Come pasto, hierba". & $\begin{array}{l}\text { 6. "Se come otros animales, } \\
\text { sallka y uywa". }\end{array}$ \\
\hline
\end{tabular}

Cuadro 1. Comparación entre los animales domesticados y silvestres.

de todos los animales. Posteriormente, el hombre recibió del mallku, en calidad de préstamo indefinido, ciertos animales que domesticó: la llama y la alpaca. No obstante, el mallku se reservó el privilegio de retomar, requisar o provocar la enfermedad o muerte de dicho ganado en el caso de que el hombre le diese mal trato o no ejecutase los ritos de rigor para propiciar su fertilidad y bienestar. Es por esta razón que los dueños de ganado hacen ritos propiciatorios en los cuales se hacen ofrendas y sacrificios (vilanchas) e invocaciones a los espíritus de la montaña y se cantan emotivas canciones a sus animales (Figuras 1a, f y 2a). Por su parte, el mallku también posee su propio rebaño constituido por todos los animales silvestres que solo él controla. Pero los pastores aymaras asignan mayor importancia a los animales domesticados que a los silvestres, por ser los primeros la base de su economía pastoril.

c) Conjuntos de contraste secundarios:

Nativo-mestizo, sagrado-profano.

Nativo-mestizo. Los pastores altiplánicos hacen distinciones precisas entre los animales domesticados de origen nativo, que asocian a sus antepasados aymara (bisabuelos o achachi), y los animales traídos por los colonos españoles a partir de la Conquista, que denominan mistti o mestizos. Así, se consideran nativos los camélidos andinos (llama y alpaca), que poseen máxima importancia en la economía pastoril de Puna; y mestizo al cordero, que ocupa un lugar subordinado en dicha economía. Dicha subordinación se externaliza en los ritos de enfloramiento de ganado, en los cuales se marca primero a las llamas hembras (mamacuya) y machos (tatacuya) y a las alpacas (pakochi) en el Jueves de Compadres presidido por el hombre; y en segundo lugar a los corderos hembras (kompitisa) y machos (torito) una semana después en el Jueves de Comadres presidido por la mujer.

Se agregan entre los animales domésticos un grupo de animales que fueron omitidos por la mayor parte de los informantes adultos, pero cuya presencia altiplánica fue constatada mediante la observación directa por la autora de este estudio, o bien por los niños pastores en sus dibujos e información verbal. Estos animales incluyen al burro, mula, cerdo, perro, gato y gallinas. Su omisión por el adulto se justifica por no ser animales nativos antiguos, por su escaso número y por no formar rebaños en el pastoreo de puna (Figura 1).

Sagrado-profano. Si bien es cierto que los animales domesticados se consideran profanos en su totalidad, a pesar de ser sacrificados al mallku en las vilanchas, la dicotomía sagrado-profano aparece nítidamente como división de los animales silvestres. Su contraste es explícito. Así, para los aymara lo sagrado es "lo que amamos", es decir, aquello que es objeto de culto o ritual; y lo profano es "lo que no amamos", todo lo no-sacro que no es objeto de culto o ritual. En consecuencia, hay animales sagrados y profanos, reconociéndose éstos por ser o no objetos de culto.

El hombre aymara de Isluga asigna gran importancia a los animales sagrados, que en dicha comunidad son ocho: tite (gato montes), chullumpe (pájaro acuático), cóndor, águila, quirquincho (armadillo), aserro (serpiente), jaririnko (lagarto) y jampato (sapo). Los cinco primeros se conservan embalsamados. El proceso de embalsamamiento consiste en llenar el pellejo emplumado del pájaro o la piel del animal previamente disecadas con lana de camélido u otro sustituto, precediéndose después a coserlo (Figuras $2 b, c, d, e, f)$.

\section{d) Paradigmas}

Del conjunto de contraste sagrado-profano se desprenden dos paradigmas: a) animales sagrados para pastoreo-comercio-agricultura; y b) animales profanos de tierra-aire-agua. Ambos paradigmas están formados por conjuntos de segregados, o categorías zoológicas étnicas que se agrupan de acuerdo a sus analogías y relaciones específicas. En el caso de los animales sagrados, su agrupación se produce por el desempeño de funciones comunes; $y$ en el caso de los animales profanos, por su relación con ámbitos espaciales y elementos naturales específicos. 
Pastoreo-comercio-agricultura. A los animales silvestres sagrados se les rinde culto para obtener beneficios para las actividades productivas. Dichos cultos dan lugar a actividades rituales asociadas al simbolismo, connotaciones y funciones propias de cada animal sagrado. En el caso de los ritos de enfloramiento del ganado, el pastor dueño de ganado suele hacer mesa (especie de altar con objetos rituales) con uno o dos tites o chullumpes, a los cuales se atribuye el poder de propiciar la fertilidad y bienestar del ganado. Tanto el tite como el chullumpe se asocian al pastoreo. Puesto que se cree que el tite es el pastor sobrenatural de los ganados silvestres del espíritu de la montaña y que sabe silbar como pastor; y que el pájaro chullumpe es el espíritu o ánima de la llama que tiene el poder de convertirse en llama, destacándose la similitud de los colores de su plumaje con los del pelaje de la llama (Figuras 2b, c).

En el Domingo de Tentación, que cierra el carnaval, se suele hacer mesa con cóndor, águila y quirquincho. Estos son ritos propiciatorios destinados a obtener éxito en las reciprocidades y transacciones comerciales. Para tal efecto, los animales se adornan con serpentinas y chaya de carnaval y se les coloca billetes en su pico u hocico (Figuras 2d, e, f).

Otros ritos privados y secretos del pastor se dedican a la serpiente, lagarto y sapo, animales asociados a la "suerte", agricultura, agua y fertilidad de la tierra. Son los animales emblemáticos de sereno, el espíritu de la música. Se les mantiene vivos dentro de pequeñas cajas en la vivienda del pastor que los posee.

Estos tres tipos de culto atestiguan la validez de las agrupaciones funcionales en el paradigma de los animales sagrados. Ellos tienen un carácter familiar y secreto. Se relacionan con los antepasados, atribuyen doseles gran antigüedad. Se cree que estos animales sagrados, junto a los demás animales profanos, se han originado en el submundo de manqhapacha, la tierra de abajo.

Tierra-aire-agua. Todos los animales silvestres (tanto sagrados como profanos) se denominan sallka, término que, según Bertonio (1879 [1612] II: 306), se refiere a las "vicuñas guanacos y animales salvajes como estos, sin dueño". En la división del paradigma de los animales silvestres profanos se distinguen animales terrestres, voladores y acuáticos, de acuerdo a su respectiva asociación más frecuente con los elementos del mundo natural.
-Los animales de tierra incluyen mamíferos (vicuña, guanaco, puma y zorro); roedores pequeños (cuye, vizcacha, añasu [zorrino] y ratón con tres variedades: achuku, tuju y wanko; y un pájaro de gran tamaño: el suri [avestruz]).

-Los animales de aire incluyen un gran número de pájaros pequeños, denominados genéricamente jamachi. Ellos incluyen algunas especies conocidas, tales como kiule (perdiz), tórtola, loro, perico y negrillo; y otros denominados kj'achi, leke-leke, kullu-kullu, takli-takli, llaka-llaka, aju-ya, takilka, ekhara, tintera, etc.; a éstos se suma la mariposa, denominada kolke-kolke o amaikhita.

-Los animales de agua reúnen a las aves acuáticas y los peces. Entre las primeras se encuentra la parina, wallata, kheillwa (gaviota) y diversos tipos de patos silvestres; los segundos se denominan genéricamente chaillwa (pez) e incluyen tres variedades: suche, burrukhatari (pejerrey) y okholli. Se reconocen numerosas especies de patos silvestres, denominados kaukala, puku-puku, unkhalle, keule, taka-taka, chuchurga, laparara, wajchi, killi-killi, etc.

Llama la atención la abundancia de términos de referencia que designan a pequeños pájaros y patos silvestres, seguidos de pequeños roedores y peces. Este fenómeno parece coincidir con un patrón cultural arcaico del norte de Chile centrado en la explotación de pequeños pájaros y mamíferos atestiguado mediante evidencias arqueológicas (Hease 1983: 1-4). Coincide, asimismo, en la actualidad, con las actividades productivas complementarias de caza-pesca-recolección desarrolladas por el niño pastor que posibilitan la diversificación de la dieta familiar. Su conocimiento de estos animales deriva de su capacidad de observación y experiencia pastoril temprana que lo vincula con su entorno natural. Dicho conocimiento articula algunas nociones etnozoológicas: el comportamiento y carácter del animal, sus hábitos y preferencias, su apariencia externa, su ubicación en su medio ambiente natural, los beneficios y peligros que presenta al hombre, su potencialidad como recurso productivo, las creencias sobre sus capacidades y poderes, su valor y utilidad como recurso productivo. Así, cada animal es categorizado de acuerdo a ciertos atributos que implican un ensanchamiento taxonómico que requiere un estudio futuro más detallado. Surgen con frecuencia las dicotomías émicas bueno-malo que alude al comportamiento pacífico/benigno o agresivo/nocivo de cada animal; y seco-húmedo, 


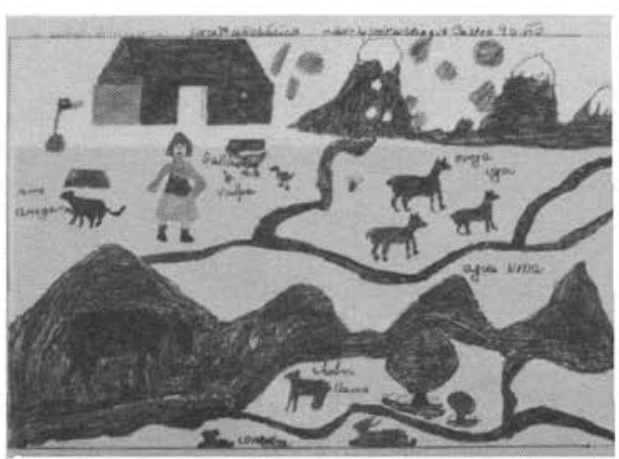

a

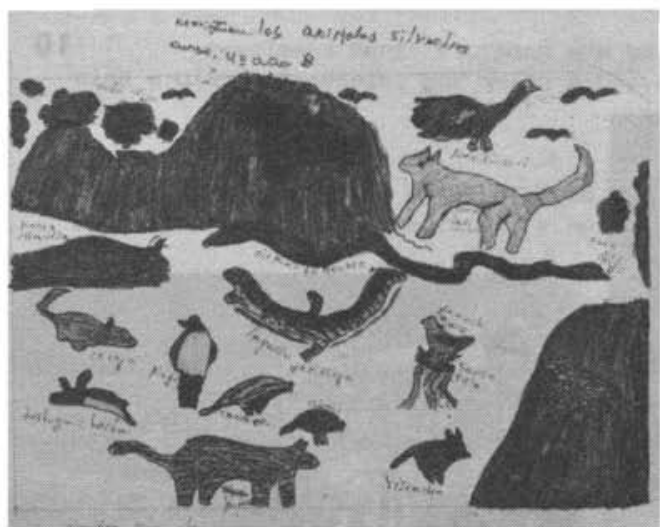

b

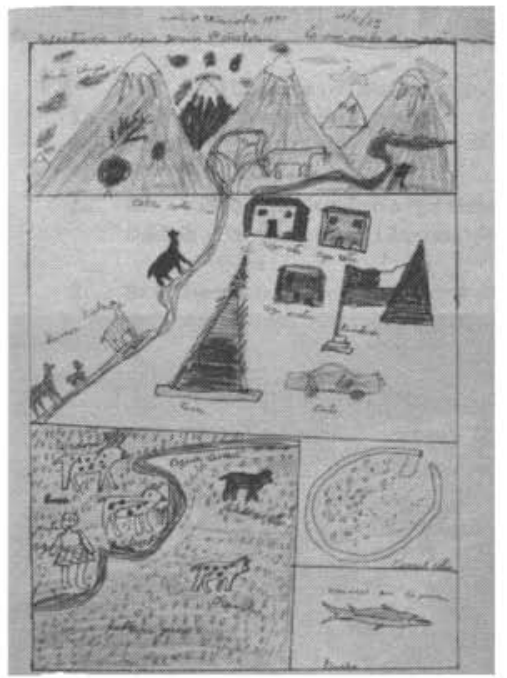

C

f

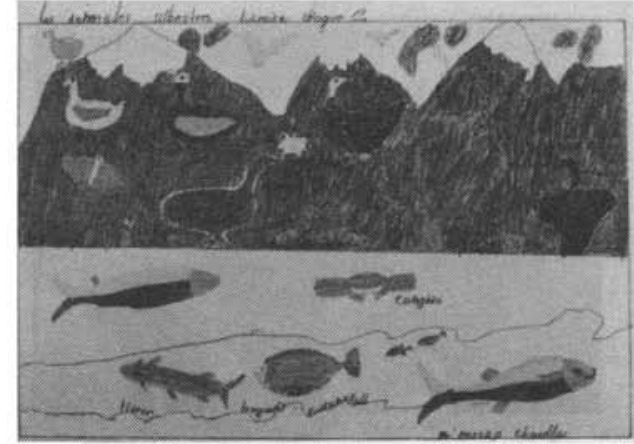

d

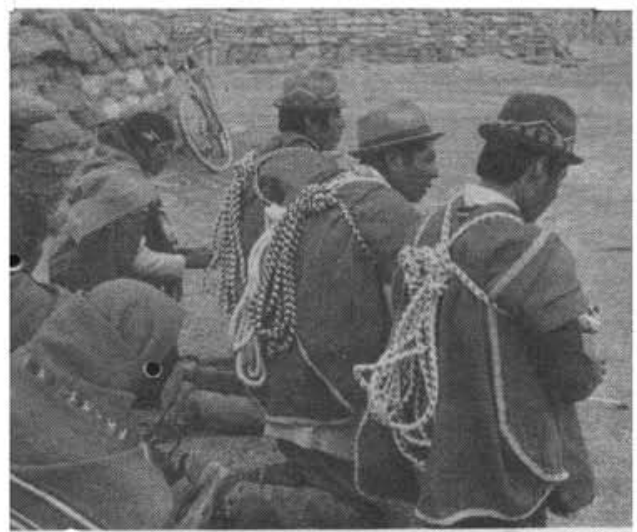

e

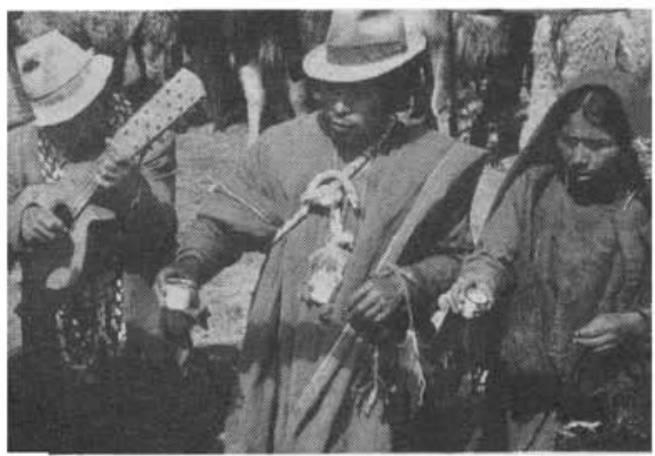

Figura 1. Etnotaxonomía zoológica. 
ETNOZOOLOGIA ANDINA: CONCEPCIONES E INTERACCIONES DEL HOMBRE ANDINO...

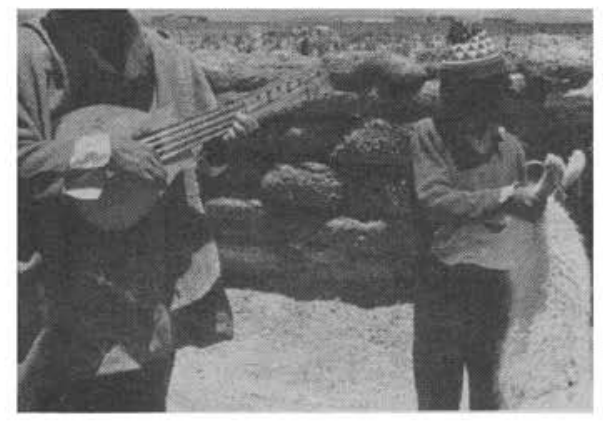

a
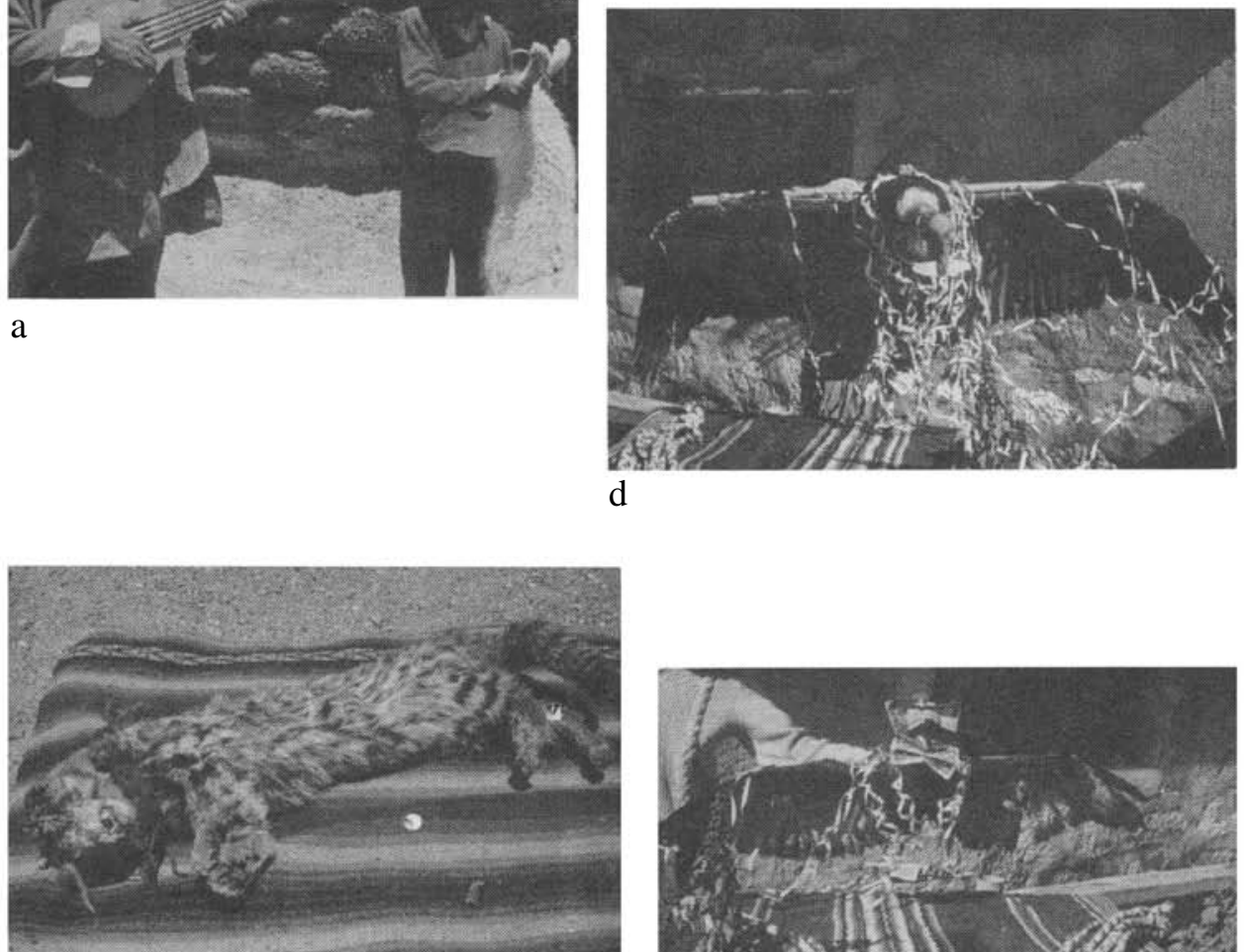

b

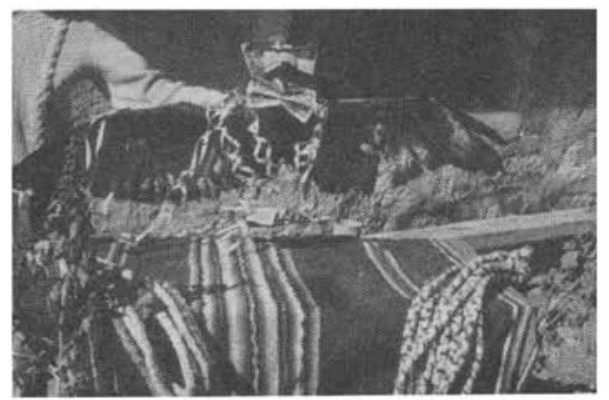

e

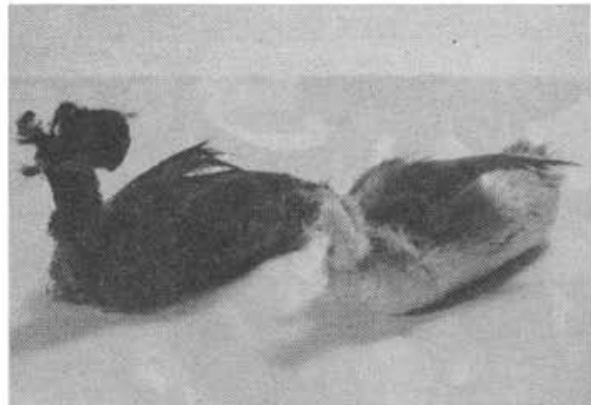

c

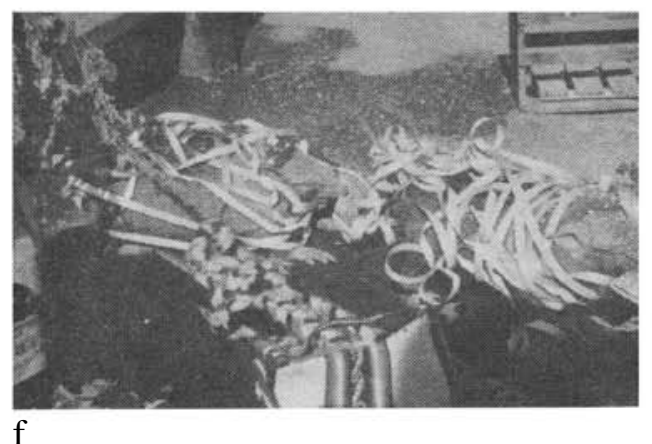

Figura 2. Etnotaxonomía zoológica. 
corral-champial (pastizal) relacionados con tierraagua. A modo de ilustración, se citan las siguientes descripciones que condensan el etnoconocimiento adquirido por el pequeño pastor de Isluga sobre dos animales silvestres:

Suri: "El suri (avestruz) es bueno, ama a la gente. Anda por cerros en seco y en agua. Se mete al agua y toma aguiita. Corre como loco, ganando a la gente. Da huevos grandes y plumas que se venden. Su carne y huevos son buenos para comer. Los huevos se sacan de sus nidos. Come sike (yerba con flor), piskayo (arbusto), come pasto, paja y monte. Puede tener dueño (domesticarse)" (D. Choque 111282).

Vizcacha: "Es animal de tierra. Anda en seco siempre, saltando de piedra en piedra por las montañas. También puede andar en lo mojado (húmedo). Es mala: pica. Cuando la persona agarra a su cría, nos persigue y nos pica del mano. Y nos quita su cría. Y se la lleva del cogote agarrando con la boca. Se sienta en el techo de las casas. Su piel color vicuña es bonita y se vende" (J. Choque 151282).

La extensión limitada del presente trabajo impide citar descripciones análogas de los restantes animales silvestres contenidos en la etnotaxonomía zoológica (ver Figura 1). Cabe señalar, sin embargo, que este etnoconocimiento empírico se refunde a menudo con creencias acerca de las capacidades y poderes mágicos atribuidos a ciertos animales. En aquellos casos de niños que han visitado o residido en el litoral o pampa, sus dibujos suelen incluir algunas especies características de esos nichos ecológicos (Figura 1d).

\section{Concepciones e interacciones}

\section{a) Aprendizaje, tradición y cambio}

Sabemos que, por tradición, el pastoreo ha sido una actividad centrada en la familia aymara (ya sea extendida o nuclear), con participación de la mayor parte de sus miembros. Sin embargo, desde hace cuatro o cinco años se ha producido un cambio adaptativo como consecuencia de una ampliación de las actividades productivas del jefe de hogar. En efecto, este último se ha convertido en transportista dueño de camión, en comerciante de frutos del país y de mercaderías importadas, en agricultor u obrero. Por este motivo, abandona su familia y estancia por períodos cada vez más prolongados.
Los testimonios entregados por los niños-pastores de Isluga describen esta situación: "Mi papá viaja mucho. Va a Iquique y a Camiña. Se queda seis días en Enquelga y luego parte de nuevo. También va a la feria de Colchane y Palpana. A mí me lleva a la feria. Tiene camión Chevrolet rojo. A mí me ha llevado a Arica, a Lluta, a Tacna, a Iquique, al Sur hasta Ovalle. Se está inscribiendo en Mitsubishi y va a tener dos camiones: el Chevrolet para acá y el Mitsubishi para abajo. Yo le ayudo a mi papá a vender en el terminal nuevo de Iquique" (M. Mamani 201282). "Mi papá trabaja en camión. Pasa casi todo el tiempo en Iquique. Compra y vende. Baja ajo, corderos, llamo; y sube fruta, cosas de almacén: arroz, harina" (V. Challapa 231282). "Mi papá se dedica a la camioneta. Pasa más abajo que arriba. Mi papá compra y vende fruta, maíz, cebolla, ajo, bebidas gaseosas, cerveza. Compra abajo y vende arriba" (L. Choque 191282). Otros padres que carecen de camiones viajan con frecuencia fuera de la estancia por motivos ligados a los patrones migratorios tradicionales. En el caso del trabajo agrícola en chacras, reciprocidades e intercambios tradicionales, a los cuales se agrega ahora la venta de productos agropecuarios en ferias andinas y mercados del litoral denotando su adaptación a la economía de mercado. Cabe señalar que la gran movilidad actual del varón aymara en vehículos de transporte es un fenómeno de origen reciente. Este tiende a suplantar al antiguo sistema de trashumancia pedestre cíclico (pasteo-costeo) de pastores y rebaños; y a debilitar el sistema tradicional de reciprocidades e intercambio correspondiente. Ambos sistemas están hoy en crisis por efectos de la sequía y de la aculturación progresiva.

En consecuencia, el varón aymara jefe de hogar delega en su esposa la responsabilidad del hogar y del pastoreo (Flores Ochoa 1979: 69). A su vez, la esposa se ve obligada a compartir deberes con sus hijos e hijas mayores de seis años, delegando en ellos la mayor parte de la rutina pastoril cotidiana. Por esta razón, en Isluga los niños de ambos sexos son adiestrados a partir de los cuatro o cinco años en las tareas más elementales, consistentes en "ayudar a atajar" animales, es decir, a mantener el orden y evitar la dispersión del rebaño. Gradualmente se le enseñan técnicas más complejas, pudiendo pastorear sólo a partir de los 5/6 ó 7/8 años. Ello depende de las habilidades de cada niño. "Aprende más rápido y es mejor pastor el niño más vivo e inteligente. El que aprende de todo: a leer, escribir, pastear, hilar, tejer" (F. Choque 181282). Al niño de las estancias 
de la mitad baja (manqha-saya), se les entrega primero un rebaño de corderos y luego el de llamos; en cambio, en las estancias de la mitad alta (araj-saya) este orden suele invertirse. Así, después de dos o tres años de entrenamiento y a partir de los $7 / 8$ años, se le entrega al pastor-niño responsabilidad sobre los dos tipos de rebaño, convirtiéndose en el eje de la rutina pastoril cotidiana y liberando a su madre de gran parte del tiempo destinado a esta actividad.

En el proceso de aprendizaje, los conocimientos de pastoreo se transmiten de madre a hijo, pudiendo ser sustituida la madre por la abuela o hermanas y hermanos mayores. Esto es un resultado de la ausencia regular del padre, que crea una situación en que los hijos pasan la mayor parte del tiempo con sus madres y se endoculturan bajo su influencia (cf. Flores Ochoa 1979). Con el fin de estimular al niño e interesarlo en las labores de pastoreo, su padre y madre le obsequian respectivamente una pareja de llama y cordero, ambas hembras, sumando un total de cuatro animales. Estos formarán, junto a todas las crías que nazcan, el rebaño propio del niño que se mantendrá integrado al rebaño familiar. "Se multiplica el ganado de acuerdo a la suerte del niño... Al casarse, él aparta su ganado" (F. Choque 181282). La motivación de los niños es obvia y explícita: "Por tener corderos y llamos le ponemos empeño al pasteo [pastoreo]" (O. Castro 211282).

\section{b) Actividades paralelas}

El aprendizaje pastoril se desarrolla como parte del aprendizaje global del niño. Por ello, se produce simultáneamente su entrenamiento en actividades domésticas, artesanales, escolares, de caza-pescarecolección y lúdicas. En las estancias, es posible compartir el pastoreo con las obligaciones escolares durante los días de semana, intensificándose la tarea pastoril y sus actividades complementarias durante los fines de semana y vacaciones.

Las actividades domésticas principales de los niños consisten en recoger leña y transportar agua; ayudar en la preparación de alimentos, aseo general, lavado de ropa y vigilancia de los hermanos menores. Las actividades artesanales difieren en el niño y la niña. El primero hila, trenza sogas y teje a palillo; la segunda hila y teje a telar objetos pequeños, tales como fajas y talegas.

En los días de semana, las actividades cotidianas del pastor-escolar consisten en sacar en la mañana los animales del corral y llevarlos al champial (pastizal) y/o al cerro (secano); y al atardecer encerrarlos en el corral. Mientras el niño asiste a la escuela de la estancia, su madre o hermanos no escolares quedan a cargo de la vigilancia del ganado. Durante los fines de semana, el niño pastorea durante todo el día junto a sus hermanos y amigos, llevándose su merienda, tejido y, quizás, sus libros de estudio. Aprovecha los numerosos momentos libres para desarrollar actividades complementarias, entre las cuales se destacan las siguientes:

-Caza-pesca-recolección. Cuando el ganado no requiere la intervención ni vigilancia del pastor, éste se dedica con frecuencia a recoger huevos de pato silvestre, de avestruz o pájaro. Su éxito dependerá de su familiaridad con el terreno y de su acceso a los lugares donde se ubican los nidos. La técnica empleada consiste en distraer al pájaro lanzando piedras o haciendo fuego. Otra actividad favorita es la pesca de peces pequeños en los canales de riego. Para ello, el niño utiliza pequeñas redes (cibiña) "arreando los pescados con un palito"; también se emplean anzuelos o la disecación del canal que permite atrapar los peces con las manos. La caza de pequeños mamíferos (tales como cuy y vizcachas) y pájaros destaca por el uso de hondas y trampas. Además, el niño se suele ocupar de la recolección de frutos y semillas silvestres comestibles. Algunas niñas suelen ordeñar corderos y preparar quesos. El producto de todas estas actividades no es consumido por el niño in situ, como sería de esperar, sino que se transporta al hogar y se entrega a la madre para la alimentación del día. En el caso de que este producto sea importante en cantidad y calidad, el niño contribuye significativamente a la alimentación de su grupo, por lo cual recibe el reconocimiento de los suyos.

-Juegos. Mientras vigila su ganado, el niño dispone de tiempo para bañarse en los canales de riego, comer su merienda y jugar en compañía de otros niños pastores y sus respectivos perros. Uno de los juegos predilectos de los niños de la mitad de abajo (manqhasaya) es jugar con barrito. Consiste en construir un pequeño mundo en miniatura con pequeñas figuras de arcilla sin cocer. Se suele reproducir animales, pastores, corrales y utensilios pastoriles con los cuales se juega a ser pastor mientras se pastorea. En efecto, las actividades lúdica y pastoril aparecen superpuestas. Y dicha superposición refuerza y enriquece el aprendizaje del pastor. "Hoy jugué con barrito. Jugué al cordero. Son cinco corderitos de 
barrito que tengo. Cuando me voy, los escondo en un hoyito tapado con matita" (A. Choque 121282). "Lo que más me gusta es jugar con barrito. Hago de todo: animalitos, autitos, pan, manzana, aceite, arroz, azúcar, ollas, cocina. Igual que adobe se hace corralito y se ponen animalitos. Juego a hacer comida también" (D. Choque 111282). En verdad, mediante este juego el niño reconstruye su versión de su mundo.

\section{c) ¿Intentos de domesticación?}

En sus relatos, el niño pastor describe, con cierta frecuencia, sus intentos de crianza o domesticación de algunos animales silvestres. Es el caso del suri, pato silvestre, parina, y otros animales. Dichas actividades son realizadas preponderantemente por los niños de las estancias de la mitad de arriba (araj-saya), contando con el beneplácito de sus padres.

-Suri (avestruz). Se procede a quitar las crías poco crecidas a la avestruz hembra. Para ello se distrae el animal con los recursos usuales: lanzando piedras y prendiendo fuego. Se les lleva luego al champial (pastizal), junto a los rebaños de llamos; o bien al patio de la casa cuando ello es posible. Se crían construyéndoles un refugio especial para pernoctar y alimentándolos con maíz y quinoa. "Mi papá pescó dos suris y los está criando. Duermen en una casita, encerrados. No se arrancan. Yo le ayudo a mi papá a cuidar los suris; a encerrarlos y darles comida" (M. Mamani 201282).

-Patos silvestres. Se utiliza una técnica similar de crianza con los patos silvestres. "Tengo patitos criados encerrados en una malla. Les hice una poza de agua. Los cuido. Les doy comida todos los días: maíz y quinoa. Los hago nadar todos los días. Los saco en la noche fuera del agua y duermen en un nido que yo hice con tablitas y puerta. No se ha muerto ninguno" (M. Mamani 201282) . "Es fácil pescar pollos de pato y huevos. Los pollitos son para criar. He criado patitos en río y los amarré. Se pusieron huachitos. Al final, se me perdieron" (L. Castro 211282) .

-Parina (flamenco rosado). La domesticación de este animal es menos frecuente. Y, por lo general, los relatos aluden a situaciones especiales. "Pesqué una parina chica que estaba medio ahogada en una laguna. La coloqué en un nido calientito de los suris. Después, le daba comida. Ahora está grande y mansita. Pone huevos que me los como yo junto con mi familia. Ahora tiene dos crías la parina. El color de sus plumas es blanco y rosado" (M. Mamani 201282).

Estos intentos de domesticación, pueden ser comprendidos en un contexto casi lúdico. En efecto, el niño pastor reconstruye el hábitat de sus animales silvestres y juega a criarlos. No obstante, en el caso de los suris la intervención de los adultos y la comercialización de los animales criados sitúa este intento de domesticación en el contexto de una experiencia pecuaria productiva.

\section{d) Comunicación}

El pastor utiliza distintos medios expresivos para hacerse entender por sus animales: la palabra hablada, los sonidos, gestos y acciones. Dichos recursos comunicativos se adecuan al carácter y conducta habitual de los diferentes animales. En general, la interacción del pastor aymara con sus animales es cálida. El los trata con amor, como si fuesen miembros de su propia familia. Les habla y los acaricia; puede amonestarlos verbalmente y castigarlos físicamente con benevolencia o severidad, igual que a un hijo. Y, durante los ritos de enfloramiento, los adorna y marca con flores multicolores de lana; y les canta dulces canciones acompañadas por bandola (Figura 2a). La canción favorita destinada al pastoreo cotidiano es awatiri, cuyo texto alude a la interacción entre pastores; y entre éstos y sus rebaños.

Pero los pastores utilizan más corrientemente un sistema de señales. Estas señales consisten en fuertes silbidos y exclamaciones tradicionales compartidas por adultos y niños. Ellas son: “ $;$ chita! ¡chita! ¡chita!...”, dirigida a los corderos; “ipiska! ipiska! ¡piska!...” y “¡kuti; ¡kuti! ¡kuti!...”, dirigidas estas dos últimas a llamos y corderos. Estas señales son complementadas por los movimientos y desplazamientos del pastor y por el ladrido y correteo de su perro. Y, en el caso específico de la llama, por el uso de la soga y un bastón. El pastor niño controla la respuesta del animal: "Yo les silbé y los llamos se dieron vuelta y se fueron a otra parte. Les silbé de nuevo y los llamos se quedaron parados allí mismo" (L. Castro 141282).

Según su comportamiento, el animal se hace merecedor de un premio o castigo. "Cuando nosotros los llamamos (a los corderos) y vienen rápido y corriendo, nosotros les regalamos leche" (M. García y D. Choque 10-1282). Por el contrario, "si no me 
hacen caso, los hondeo con una piedra..." (O. Vilches 141282); "o les pego con un palo..." (S. Vilches 141282). Cuando se pierde una cría, "la encontramos y le pegamos y las dejamos sin mamar y las encerramos en el corral..." (S. Choque 101282). Los animales responden a menudo favorablemente a estos castigos, aprendiendo así a obedecer al pastor.

Los pastores niños juegan habitualmente con sus animales regalones o traviesos. Ellos recuerdan vívidamente algunas de estas experiencias lúdicas, en las cuales la comunicación entre el niño y el animal se intensifica, alcanzando niveles de cálida expresividad. "Yo tenía un cordero. Y estaba jugando y el huacho me perseguía. Y yo me escondía en el monte y el huacho... allí estaba" (R. Castro 141282). "Yo tenía un cordero muy habiloso. Me hacía reír mucho, como un gente" (M. Mamani 141282).

En verdad, el pastoreo del niño aymara es vida. Ofrece un panorama vivo, desde el interior de la matriz cultural, del proceso de endoculturación del pequeño pastor. Da una imagen auténtica de sus concepciones y de su red de interacciones con su familia y rebaños.

\section{Resumen y discusión}

Este trabajo no pretende sino dejar iniciada una indagación sobre aspectos cognitivos del pastoreo andino de Puna en la I Región de Chile. Se ha intentado identificar sus modelos de representación mediante la reconstrucción de una etnotaxonomía zoológica que permite captar cómo concibe el hombre andino su fauna. Se ha intentado, asimismo, complementar este marco conceptual incursionando en los modelos operacionales del pastor, implícitos en su praxis del pastoreo y actividades relacionadas (Caws 1974: 3-4).

Sus resultados indican:

1. Se revela la existencia de una etnozoología que refleja una concepción ordenada del reino animal altiplánico chileno, que propone un sistema de nociones jerarquizadas provisorias y permite comprender las relaciones entre el hombre andino y su fauna.

2. Se rescata una etnotaxonomía zoológica que denota una marcada selectividad. Aparecen en ella sólo algunas clases y especies de animales característicos de la fauna regional, contándose entre ellos mamíferos, aves (pájaros), peces, reptiles y anfibios. Con excepción de la mariposa, los insectos son omitidos, al igual que todos los artrópodos y moluscos, gusanos y microorganismos. Estas omisiones se extienden a ciertas aves de corral y mamíferos domesticados que no constituyen rebaños (ver Figura 1) .

3. Los animales regionales se agrupan en conjuntos de contraste y paradigmas basados respectivamente en dicotomías y divisiones émicas. Ellas son: domesticado-silvestre, nativo-mestizo, sagrado-profano, pastoreo-comercio-agricultura, tierra-aire-agua. Constituyen un reflejo de las percepciones, concepciones e interacciones del pastor altiplánico respecto a su fauna regional.

4. Destaca la importancia asignada a los ocho animales sagrados, los cuales son objeto de culto en los ritos de enfloramiento de ganado y carnaval. Dichos animales se asocian funcionalmente a las tres actividades productivas tradicionales básicas de los aymaras: pastoreo, agricultura y reciprocidad-intercambio. Se cree que ejercen su poder propiciando el éxito (o suerte) en dichas actividades.

5. Se estudia el aprendizaje del pastor-niño en el contexto de un proceso de cambio sociocultural en marcha; las actividades paralelas al pastoreo, incluyéndose las domésticas, artesanales, escolares, de caza-pesca-recolección y lúdicas; los nuevos intentos de domesticación; y los recursos comunicativos con los rebaños. Todo ello revela las formas en que se dan las interacciones entre los niños-pastores y su fauna; y la riqueza de sus matices humanos, tanto afectivos como cognitivos. En dicho contexto, surgen las explicaciones. Y de ellas la posibilidad de comprender, "desde dentro", la vida del pequeño pastor.

En este trabajo se ha pretendido solamente presentar los resultados de una aproximación émica a la realidad del pastor altiplánico, depurando la descripción y descartando lo obviamente trivial.

La etnotaxonomía zoológica es expresiva. Refleja procesos selectivos del hombre altiplánico. En ella, aparece lo que él reconoce como importante, involucrando tanto aquellos animales que benefician sus tareas productivas como aquellos que las obstaculizan. Todos ellos son nombrados con sus propios términos de referencia en uso, en aymara y/o español. Pero 
desaparece lo que no se nombra y omite. Queda en evidencia que el pastor ha dejado fuera varias clases y especies animales que existen en su entorno habitual (tales como moluscos, artrópodos, insectos y gusanos). ¿Es que él no los reconoce ni categoriza como animales? ¿O no los considera dignos de mención? ¿O permanecen éstos en el ámbito de lo prohibido o ignorado? Estas y otras incógnitas merecerían en el futuro un estudio separado.

La etnotaxonomía zoológica es un modelo de representación. Refleja ideas, conocimientos y creencias del hombre altiplánico. Pero también revela una red de interacciones: la del hombre con su fauna, la del hombre con lo que él concibe como fauna. Esta red de interacciones específicas de los pastores con sus animales domesticados y algunos silvestres, su propia percepción de dichas interacciones, nos dan la clave para comprender no solamente una etnozoología andina en sí misma, sino también al hombre andino en su contexto; y para comprender, asimismo, la interdependencia de sus ideas y su conducta respecto a su fauna: lo que conoce y lo que pone en práctica.
Por otra parte, el estudio de las concepciones e interacciones del pastor ha permitido captar la adaptación y ajuste continuos de sus pautas culturales y sociales frente a una realidad cambiante; frente a una naturaleza que se ensancha o empequeñece en la mente del pastor; $y$ frente a un descubrimiento y valorización de lo que ofrece la cultura urbana. Puesto que esta realidad cambiante es percibida con matices afectivos, se replantean sus relaciones con los demás hombres, con la naturaleza, lo sobrenatural y el reino animal.

Agradecimientos Hago extensivos mis agradecimientos y gratitud a los niños de ambas escuelas, quienes con su motivación, entusiasmo, honestidad y alegría, hicieron de este trabajo una experiencia inolvidable para la investigadora. Y a la Dra. Billie Jean Isbell, de Cornell University, por su valiosa comunicación personal de febrero, 1981, respecto a su experiencia con diarios de vida de campesinos andinos, que influyó decisivamente en los métodos y técnicas empleadas en este trabajo.

\section{REFERENCIAS CITADAS}

ALBERTI, G. y E. MAYER (Eds.), 1974. Reciprocidad e intercambio en los Andes peruanos. Instituto de Estudios Peruanos, Lima.

ALDUNATE, C. et al., 1981. Estudio etnobotánico en una comunidad precordillerana de Antofagasta: Toconce. Boletín del Museo Nacional de Historia Natural 38: 183-223.

ARANGUREN, A., 1975. Las creencias y ritos mágicos religiosos de los pastores puneños. Allpanchis 8: 103-132.

BAKER, P. T. y M. A. LITTLE (Eds.), 1976. Man in the Andes. Dowden, Hutchinson \& Ross, Stroudsburg.

BERTONIO, L., 1879 [1612]. Vocabulario de la lengua aymara. Teubner, Leipzig.

BOUYSSE-CASSAGNE, T., 1978. L'espace aymara. Urco et uma. Annales E.S.C. 5-6: 1057-1080.

CASAVERDE, J., 1970. El mundo sobrenatural en una comunidad. Allpanchis 2: 121-243.

CASTRO, M., C. VILLAGRAN y M. KALIN, 1982. Estudio etnobotánico en la precordillera y altiplano de los Andes del norte de Chile. En El hombre y los ecosistemas de montaña, A. Veloso y E. Bustos (Eds.), pp. 133-203. UNESCO Montevideo.

CAWS, P., 1974. Operational, representational and explanatory models. American Anthropologist 76: 1-10.
CERECEDA, V., 1978. Sémiologie des tissus andins: Les talegas d'Isluga. Annales E.S.C., 5-6: 1017-1035.

CONCHA CONTRERAS, J. de D., 1975. Relación entre pastores y agricultores. Allpanchis 8: 67-103.

CONKLIN, H. C., 1969. Lexicographical treatment of folk taxonomics. En Cognitive anthropology, S. Tyler (Ed.), pp. 41-59. Holt, Rinehart \& Winston, Nueva York.

DURKHEIM, E. y M. MAUSS, 1963. Primitive classification. The University of Chicago Press, Chicago.

DYSON-HUDSON, R. y N. DYSON-HUDSON, 1980. Nomadic pastoralism. Annual Review of Anthropology 9: 15-61.

EARLS, J., 1973. La organización del poder en la mitología quechua. En Ideología mesiánica del mundo andino, J. Ossio (Ed.). Lima.

FLORES OCHOA, J. A., 1976. Enqa, enqaychu, illa y khuya rumi: Aspectos mágico-religiosos entre pastores. Journal of Latin American Lore 2 (1) 115-134.

(Ed.), 1977a. Pastores de Puna. Instituto de Estudios Peruanos, Lima.

1977b. Pastoreo, tejido e intercambio. En Pastores de Puna, J. Flores Ochoa (Ed.), pp. 133-154. Instituto de Estudios Peruanos, Lima. 
1978. Classification et denomination des camélidés sudaméricains. Annales E.S.C. 5-6: 1006-1016.

1979. Pastoralists of the Andes. Institute for the Study of Human Issues, Filadelfia.

FONSECA, C., 1972. Sistemas económicos en las comunidades campesinas del Perú. Tesis Doctoral. Universidad Nacional Mayor de San Marcos, Lima.

FRAKE, C. O., 1969a. The ethnographic study of cognitive systems. En Cognitive anthropology, S. Tyler (Ed.), pp. 28-41. Holt, Rinehart \& Winston, Nueva York.

1969b. Notes on queries in ethnography. En Cognitive anthropology, S. Tyler (Ed.), pp. 123-137. Holt Rinehart \& Winston, Nueva York.

GARR, T. M., 1972. La familia campesina y el cosmos sagrado. Allpanchis 4: 7-19.

GOW, D., 1974. Taytacha qoyllur rit'i: Rocas y bailarines, creencias y continuidad. Allpanchis 7: 49-100.

GOW, D. y R. GOW, 1975. La alpaca en el mito y el ritual. Allpanchis 8: 141-164.

GREBE, M. E., 1975. Taxonomía de enfermedades mapuches. Antropología 2: 27-39.

_ 1980. Generative models, symbolic structures and acculturation in the panpipe music of Tarapacá, Chile. Tesis Doctoral. The Queen's University of Belfast, Belfast.

1981. Cosmovisión aymara. Revista de Santiago 1: 61-79.

HARTMANN, R., 1971. Algunas observaciones respecto al trueque y otras prácticas en las ferias de la sierra ecuatoriana. Archiv. für Volkerkunde 23: 43-53.

HESSE, B., 1983. Archaic exploitation of small mammals and birds in Northern Chile. Estudios Atacameños 7, este volumen.

ISBELL, B. J., 1978. To defend ourselves: Ecology and ritual in an Andean village. Institute of Latin American Studies, Austin.

LEVI-STRAUSS, C., 1964. El pensamiento salvaje. Fondo de Cultura Económica, México D. F.

LEWELLEN, T. C., 1977. The Aymara in transition; Economy and religion in a Peruvian peassant community. Tesis Doctoral. University of Colorado, Boulder.

MARTINEZ, G., 1976. El sistema de los uywiri en Isluga. Universidad del Norte, Centro Isluga de Investigaciones Andinas, Iquique.
MATOS, J., 1976. Comunidades indígenas del Area Andina. En Hacienda, comunidad y campesinado en el Perú, J. Matos (Ed.), pp. 179-217. Instituto de Estudios Peruanos, Lima.

MAYER, E., 1974. Reciprocity, self-sufficiency and market relations in a contemporary community in the Central Andes of Perú. Tesis Doctoral, Cornell University, Ithaca.

MURRA, J., 1975. Rebaños y pastores en la economía del Tawantinsuyo. En Formaciones económicas y políticas del mundo andino, J. Murra (Ed.), pp. 117-144. Instituto de Estudios Peruanos, Lima.

NORDYKE, Q., 1972. Animistic Aymara and church growth. The Barclay Press, Newberg.

NUÑEZ DEL PRADO, J., 1970. El mundo sobrenatural de los quechuas del sur del Perú... Allpanchis 2: 57-119.

OBEREM, U., 1967. Trade and trade goods in the Ecuadorian montaña. Folk 8-9: 243-258.

ORLOVE, B. S., 1977. Alpacas, sheep, and men: wool export economy and regional society in Southern Perú. Academic Press, Nueva York.

PELTO, P. y G. H. PELTO, 1978. Anthropological research: The structure of inquiry. Cambridge University Press, Cambridge.

PIKE, K., 1954. Language in relation to a unified theory of human behavior. Summer Institute of Linguistics, Glendale.

SALLNOW, M. J., 1974. La peregrinación andina. Allpanchis 7: $101-142$.

STURTEVANT, W. C., 1968. Studies in ethnoscience. En Theory in anthropology: A sourcebook. R. A. Manners y D. Kaplan (Eds.), pp. 475-500. Routledge \& Kegan Paul, Londres.

THOMAS, R. B., 1972. Human adaptation to a High Andean energy flow system. Tesis Doctoral. Pennsylvania State University, Pennsylvania.

VAN KESSEL, J., 1980. Holocausto al progreso. Centro de Estudios y Documentación Latinoamericanos, Amsterdam.

WALLACE, A. F. C., 1962. Culture and cognition. Science 135: 351-357.

WEBSTER, S. S., 1971. An indigenous quechua community in exploitation of multiple ecological zones. Revista del Museo Nacional 37: 174-183.

1973. Native pastoralism in the Southern Andes. Ethnology 12: 115-133. 